\title{
A NOVEL DESIGN AND DEVELOPMENT OF COMPACT GAP COUPLED RECTANGULAR MICROSTRIP ANTENNA FOR WIDEBAND APPLICATIONS
}

\author{
Kalpana Chikatwar ${ }^{1}$, S. N. Mulgi ${ }^{2}$ \\ ${ }^{1}$ Department of P. G. Studies and Research in Applied, Electronics, Gulbarga University, Kalaburagi-585 106, \\ Karnataka, India \\ ${ }^{2}$ Professor, Department of P. G. Studies and Research in Applied Electronics, Gulbarga University, Kalaburagi-585 \\ 106, Karnataka, India
}

\begin{abstract}
In this paper we have presented a novel design and development of partial ground plane gap coupled corner truncated rectangular microstrip antenna (GCTRMA) for wideband application. The proposed antenna is simple in its geometry and can be constructed by splitting the rectangular monopole MSA along its width and then by truncating its corner part which act as parasitic patch element. This technique helps in getting the wide band operation of antenna. The antenna operates in the frequency band of $1.85 \mathrm{GHz}$ to $6.75 \mathrm{GHz}$ and gives maximum impedance bandwidth of $113.8 \%$ and peak gain of $8.75 \mathrm{~dB}$ in its operating band. The antenna resonates at two frequencies viz., 3.64 and $4.79 \mathrm{GHz}$ and exhibits omni-directional radiation characteristics over the entire frequency band. This antenna is very compact and simple in the structure and can be realized using low cost glass epoxy substrate material and may find application in microwave communication systems.
\end{abstract}

Keywords: Gap Coupled Truncated Rectangular Microstrip Antenna, Partial Ground, Wide Band, Gain.

\section{INTRODUCTION}

Microstrip antennas are widely used for many industrial and military applications by virtue of its various advantages such as low profile, less weight, easy fabrication and omnidirectional radiation characteristics. The main handicap of microstrip antennas is its narrow impedance band-width. A good number of papers have been published in technical literature on band-width improvement of microstrip patch antennas using additional resonators which are gap coupled to the driven patch along the radiating and non-radiating edge [1-4]. However, there are mainly two problems associated with these methods. Firstly These techniques, uses parasitic resonators which have nearly same dimensions as that of the original MSA, makes overall increase in size hence they are not suitable as array elements. Secondly distortion of radiation pattern at different frequencies in their operating band [5-10]. To overcome these problem, If a microstrip antenna(MSA) is splitted into smaller elements, which has nearly the same resonance frequency as that of the original MSA, then band width can be improved by suitably gap-coupling with these splitted elements. In this paper a broadband microstrip antenna is realized by splitting radiating patch into smaller elements. By truncating the corner top and bottom part of splitted parasitic patch the wide band operation can be achieved .The designed gap-coupled antenna configuration is compact in size whereas the corner cut designs maintains the low profile nature of the antenna.

\section{ANTENNA CONFIGURATION}

The configuration of the proposed gap-coupled corner truncated rectangular microstrip antenna (GCTRMA)is shown in Fig-1 shows . The antenna is printed on a $1.6 \mathrm{~mm}$ thick gloss epoxy dielectric substrate of relative permittivity $\left(\varepsilon_{\mathrm{r}}\right) 4.2$ and loss tangent $(\delta) 0.05$ with size of Ws $\mathrm{x}$ Ls. The antenna consists of a radiating patch of width 'Wp' and length ' $\mathrm{Lp}$ ' $\mathrm{mm}$. The radiating patch is splitted along nonradiating edge with a gap of $1 \mathrm{~mm}$.Then the parasitic patch is truncated at left top and bottom corner as shown in fig.1.The antenna is fed using a single $50 \Omega$ microstripline and this feedline is connected to $50 \Omega$ SMA connector for excitation. The length of feed is $(\mathrm{Lg}+\mathrm{g})=$ $27.7 \mathrm{~mm}$ and width $\mathrm{W}_{\mathrm{f}}=3.2 \mathrm{~mm}$. A partial copper ground plane of height $\mathrm{Lg}=26 \mathrm{~mm}$ is placed below the microstripline feed on the bottom layer of the substrate. The gap between the partial ground plane and radiating patch is $\mathrm{g}=1.7 \mathrm{~mm}$. The simulation work of antenna is carried out by using Ansoft HFSS software [11]. 


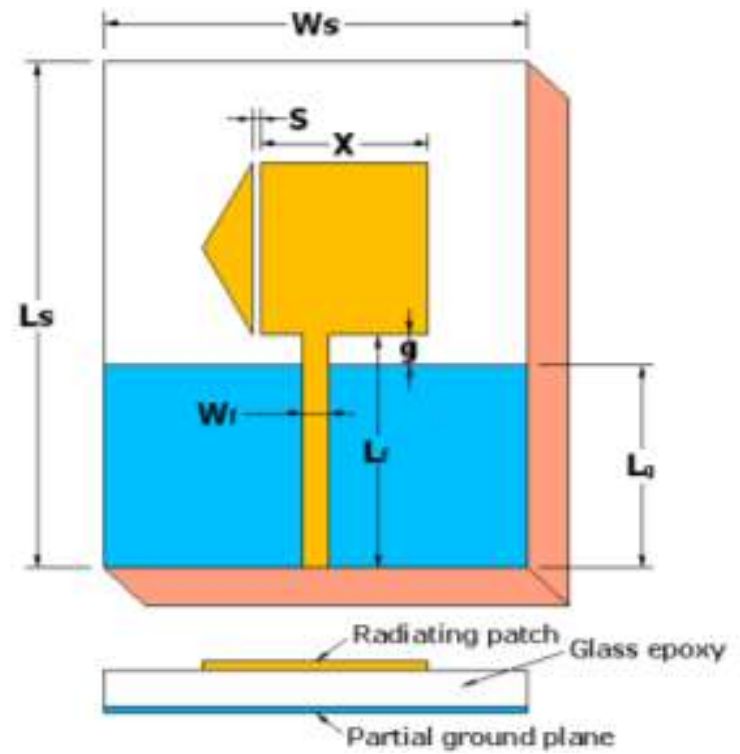

Fig-1: Top view geometry of proposed GCTRMA

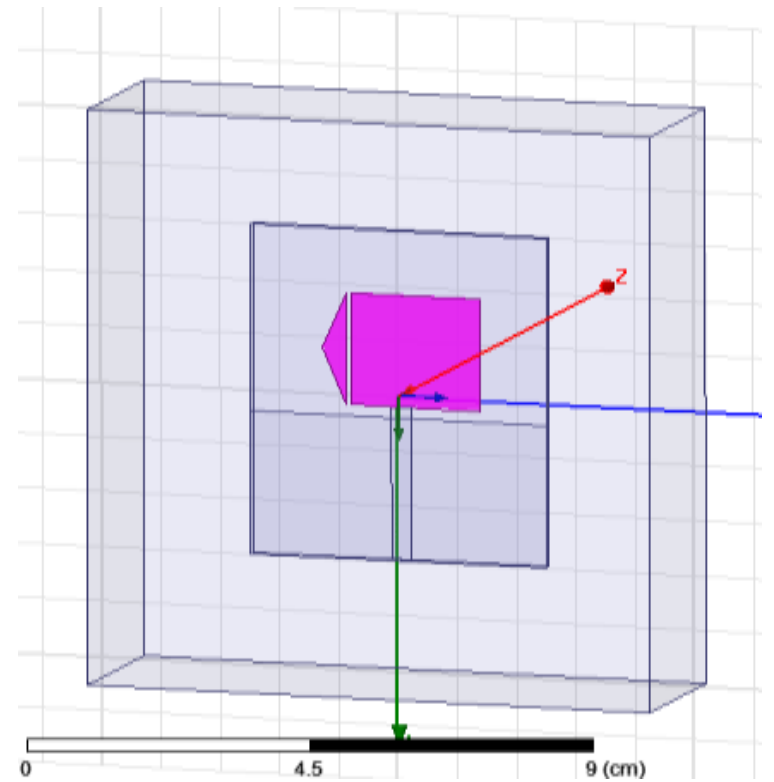

Fig-2: HFSS model of the proposed GCTRMA.

The design parameters of the proposed antennas are given in Table-1. The HFSS model of the proposed antenna is shown in Fig.3.

Table-1: Design parameters of the proposed GCTRMA

\begin{tabular}{|l|l|}
\hline Antenna parameter & Dimensions (in mm) \\
\hline $\mathrm{W}_{\mathrm{p}}$ & 26.6 \\
\hline $\mathrm{L}_{\mathrm{p}}$ & 20.4 \\
\hline $\mathrm{W}_{\mathrm{f}}$ & 3.2 \\
\hline $\mathrm{L}_{\mathrm{f}}$ & 21.8 \\
\hline $\mathrm{g}$ & 1.7 \\
\hline $\mathrm{h}$ & 1.6 \\
\hline $\mathrm{L}_{\mathrm{g}}$ & 26 \\
\hline $\mathrm{W}_{\mathrm{s}}$ & 60 \\
\hline $\mathrm{Ls}$ & 50 \\
\hline $\mathrm{S}$ & 1 \\
\hline $\mathbf{X}$ & 21.6 \\
\hline
\end{tabular}

\section{RESULTS AND DISCUSSION}

The variation of return loss versus frequency of GCTRMA is as shown in Fig-3. From the figure, it is clear that, the proposed antenna operates for wide bands of frequencies and gives a maximum impedance bandwidth of $\mathrm{BW}=113.8 \%(1.85 \mathrm{GHz}$ to $6.75 \mathrm{GHz})$, with a peak gain of $8.75 \mathrm{~dB}$ measured in its operating band.

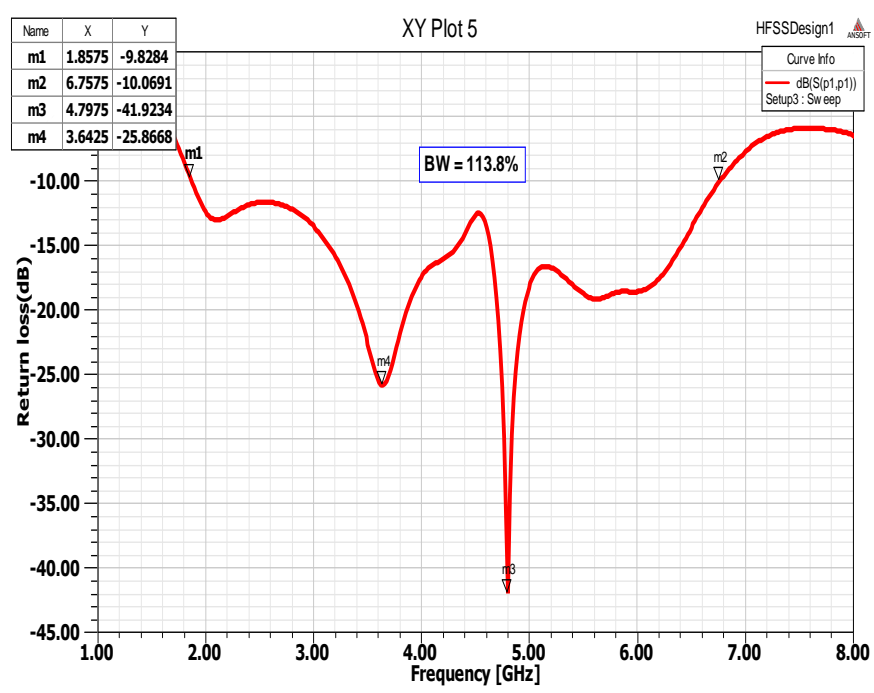

Fig-3: Variation of return loss versus frequency of GCTRMA.

A typical 2D and 3D E-plane and H-plane radiation patterns of proposed antenna measured at the resonant frequencies 3.64 and $4.79 \mathrm{GHz}$ is shown in Fig-4 and Fig-5 respectively. The obtained radiation patterns are nearly omni-directional in nature.

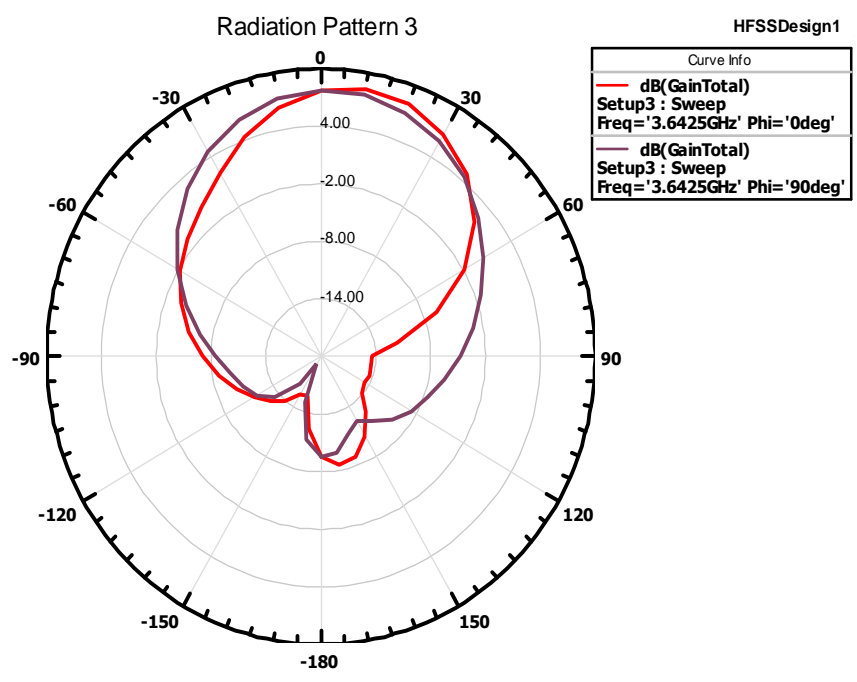




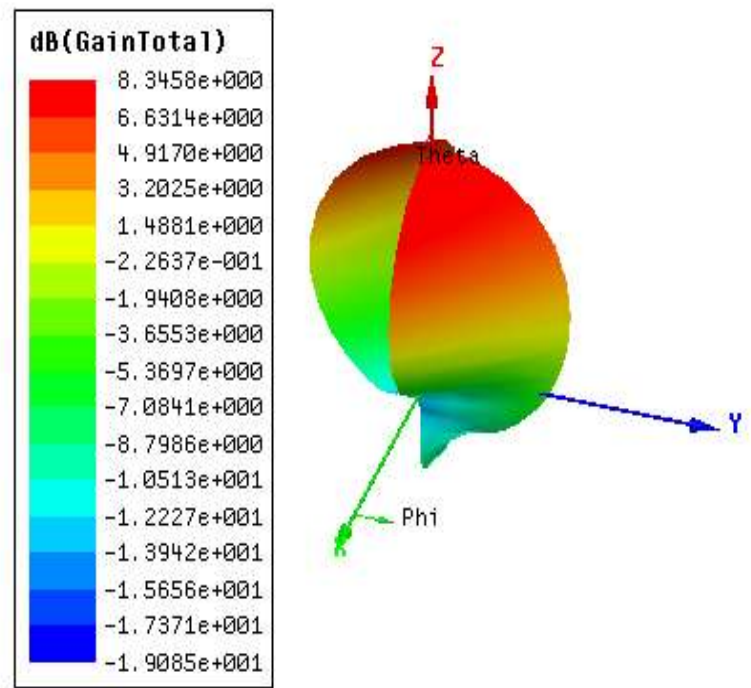

Fig-4: Radiation pattern of GCTRMA measured at 3.64 $\mathrm{GHz}$
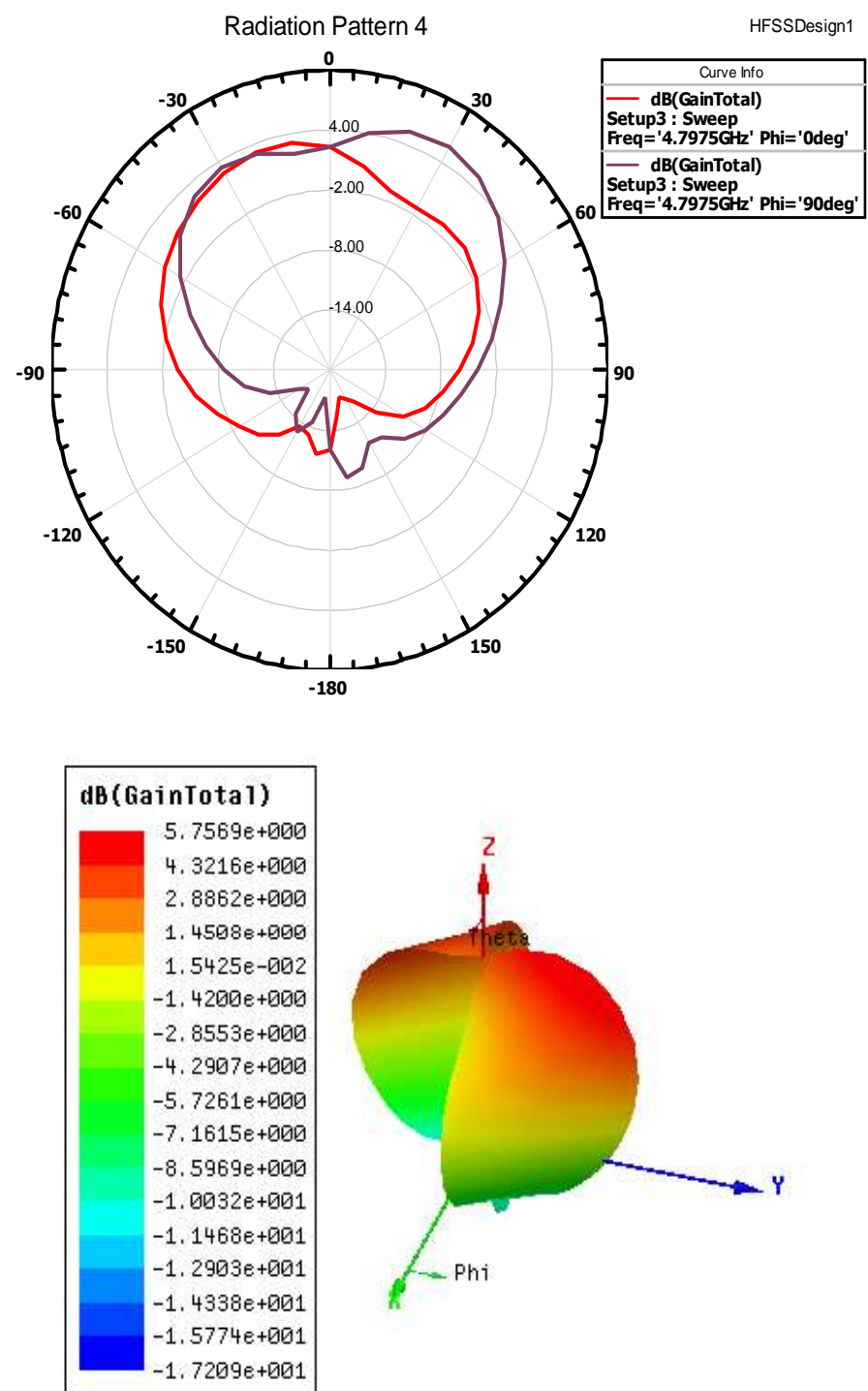

Fig-5: Radiation pattern of GCTRMA measured at $4.79 \mathrm{GHz}$
Figure-6 shows surface current distributions of GCTRMA .From these figures it is seen that, the current distribution is observed towards the edge point of the microstripline feed, at the gaps on patch and uniform current distribution is also observed at the ground plane surface of the antenna causing wideband operation.
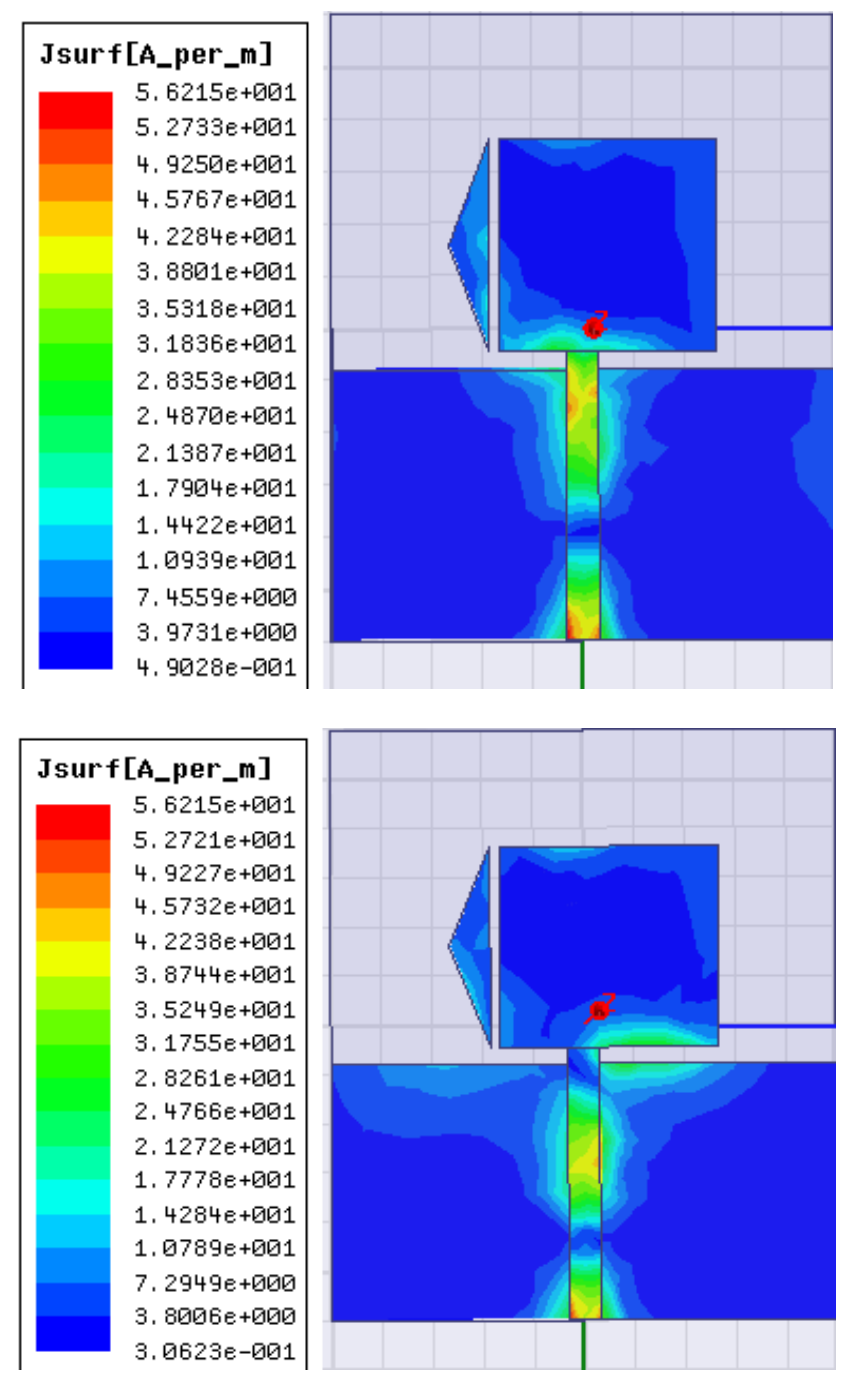

Fig-6: Current distribution of GCTRMA measured on patch and ground plane surfaces at $3.64 \mathrm{GHz}$ and $4.79 \mathrm{GHz}$

\section{CONCLUSION}

A simple compact gap coupled corner truncated rectangular microstrip antenna with partial ground plane is presented for wide band operation. The antenna operates in the frequency range of $1.85 \mathrm{GHz}-6.76 \mathrm{GHz}$ and gives an impedance bandwidth of $113.8 \%$.The antenna is fed by simple microstripline feed yields acceptable VSWR of less than 2. As the parasitic element is obtained from the radiating patch itself, the designed antenna is simple in its configuration and compact in nature and can be fabricated using low cost modified glass epoxy substrate material and may find the applications in GPS mobile phones, WLAN, WiMax and Bluetooth etc. The radiation pattern is almost omnidirectional over the entire bandwidth with a peak gain of $8.71 \mathrm{~dB}$. 


\section{REFERENCES}

[1]. Constantine A. Balanis, Antenna theory analysis and design, John Wiley, New York, 1997.

[2]. I. J. Bahl and P.Bharatia, Microstrip antennas, Dedham, MA: Artech House, New Delhi, 1981.

[3]. Kumar G. and Gupta K. C., 'Broadband Microstrip Antennas Using Additional Resonators Gap Coupled to the Radiating Edge', IEEE Trans. Antennas Propagation, 1984, 32, pp.1375-1379.

[4]. Kumar, G., and Gupta, K. C.: 'Non radiating edges and four edges gap coupled with multiple resonator, broadband microstrip antennas', IEEE Trans. Antennas Propagation, 1985, 33, pp. 173-178.

[5]. Kumar, G., and Ray, K. P., 'Broadband microstrip antennas' (Artech House, Boston, 2003)

[6]. K. P. Ray, V. Sevani and A. A. Deshmukh "Compact Gap-coupled Microstrip Antennas for Broadband and Dual Frequency Operations" ,International journal of microwave and optical Technology, Vol.2, NO .3, july 2007.

[7]. K. P. Ray, V. Sevani, and R. K. Kulkarni "Gap coupled rectangular Microstrip antennas for dual and triple frequency operation "International journal of microwave and optical Technology, Vol. 48, No. 12, December 2006.

[8]. K.P. Ray, V. Sevani, and S. Kakatkar, Compact broadband gap coupled rectangular microstrip antennas, Microwave And Optical Technology Letters / Vol. 48, No. 12, December 2006

[9]. Amit A. Deshmukh and Girish Kumar" Compact Broadband Rectangular Microstrip Antenna" Microwave and Optical Technology Letters / Vol. 48, No. 6, June 2006

[10]. C.K. Anandan, P.K. Mohanan, and K.G. Nair, Broadband gap coupled microstrip antennas,IEEE Trans Antennas Propagation. 38 (1990), 1581- 1586

[11]. Ansoft HFSS, 3D EM-field simulation for high performance electronic design. ver. 11, Ansoft Corp., Pittsburgh, PA, 2008. 